\title{
Respiratory Rate as a Predictor of Weaning Failure from Mechanical Ventilation
}

\author{
Emídio Jorge Santos Lima* 1
}

1. MD Intensivist, Associacao de Medicina Intensiva Brasileira (Amib); Coordinator and Daily Physician at the Intensive Care Unit, Hospital Geral de Camacari; Master of Computational Modeling; PhD in Knowledge Diffusion, Universidade Federal da Bahia (UFBA), Salvador, BA, Brazil

Received from the Intensive Care Unit of Hospital Geral de Camacari, Camacari, BA, Brazil.

Submitted on January 27, 2012 Approved on April 2, 2012.

\section{Keywords:}

Respiration, Artificial;

Respiratory Rate;

Ventilator Weaning.

\begin{abstract}
Background and objective: There is not an ideal predictor of weaning from mechanical ventilation (MV). In a large meta-analysis, despite methodological limitations, respiratory rate (RR) was considered a promising predictor. The aim of this study was to evaluate RR as a predictor of weaning failure from MV.

Methods: We prospectively evaluated 166 patients scheduled for weaning from MV. RR and other essential criteria for weaning were evaluated at an early stage of screening. Patients who met the essential screening criteria for weaning underwent spontaneous breathing trial. RR was compared with the following outcomes: weaning success/failure or extubation failure.

Results: Weaning success was present in $76.5 \%$ and weaning failure in $17.5 \%$ of patients. There were $6 \%$ of reintubations. The predictive power for RR weaning failure, RR best cut-off point $>24$ breaths per minute (rpm), was: sensitivity $100 \%$, specificity $85 \%$, and accuracy $88 \%$ (ROC curve, $\mathrm{p}<0.0001)$. Of the patients with weaning failure, $100 \%$ were identified by RR during screening (RR cut-off > $24 \mathrm{rpm}$ ). There were 15\% false positives, weaning successes with RR > $24 \mathrm{rpm}$.

Conclusion: RR was an effective predictor of weaning failure. The best cut-off point was RR > $24 \mathrm{rpm}$, which differed from those reported in the literature (35 and $38 \mathrm{rpm}$ ). Only $6 \%$ of patients were reintubated, but RR or other weaning criteria did not identify them.

๑ 2013 Sociedade Brasileira de Anestesiologia. Published by Elsevier Editora Ltda. All rights reserved.
\end{abstract}

* Corresponding author: Rua Manoel Gomes de Mendonça, 207/104 Pituba 41810-820 - Salvador, BA, Brazil

E-mail: emidio.lima@gmail.com.

\section{Introduction}

According to the $6^{\text {th }}$ International Consensus Conference in Intensive Care Medicine, patients who meet the essential criteria for weaning from mechanical ventilation (MV) - particularly improvement of the cause of respiratory failure, oxygenation, appropriate respiratory mechanics, and hemodynamic stability - should be evaluated for the possibility of 
weaning. In this context, a predictor, such as the rapid shallow breathing index (RSBI), is initially used as screening and if the result is positive for weaning success, a spontaneous breathing trial (SBT) is started. If the patient passes this test, $M V$ is discontinued and followed by extubation ${ }^{1}$. The problem is that, despite all systematization of the weaning process, backed by different studies that establish the various steps of this process, the average rate of weaning failure is $30 \%$, which is associated with increased morbidity and mortality ${ }^{1-7}$. According to Epstein et al. ${ }^{6}$, weaning failure, particularly extubation failure, is associated with $43 \%$ mortality compared to $12 \%$ among those with weaning success.

In addition to the previous problem, there is not an ideal predictor of successful weaning. In the largest systematic review of predictors of successful weaning conducted by Meade et al. ${ }^{8}$ and involving 65 studies, the studied indices' predictive ability was considered modest, with RR and RSBI considered promising (sensitivity $88 \%$ /specificity $47 \%$ and sensitivity $96 \%$ /specificity $73 \%$, respectively). In most of the 65 analyzed studies, methodological flaws, such as less than 50 patients per study and statistical deficiencies, decreased the results' accuracy ${ }^{8}$. In a recent publication, a new predictor resulting from the integration of three other predictors was presented: oxygen saturation $\left(\mathrm{SaO}_{2}\right)$, RSBI (obtained by dividing RR by tidal volume: $R R / \mathrm{V}_{\mathrm{T}}$ ), and static compliance (Cst). However, the study's major limitation was the measurement of this last variable with the patient without sedation and breathing spontaneously, which usually hinders Cst measurement ${ }^{9}$.

The aim of this study was to evaluate RR as a predictor of weaning failure from MV.

\section{Method}

After approval by the Ethics Committee (025/2006), this prospective study was conducted from March 2009 to August 2011, during which we analyzed the weaning of 166 patients admitted to the Intensive Care Unit (ICU) - with eight beds - of the Hospital Geral de Camaçari (BA). All patients (or their guardians) included in the study signed an informed consent form (ICF).

Patients underwent discontinuation of MV, according to the ICU medical staff guidance.

The study included 166 patients aged over 18 years who met the essential criteria for weaning, according to the $6^{\text {th }}$ International Consensus Conference in Intensive Care Medicine:

a) Improvement of the condition that lead to VM;

b) Discontinuation of sedatives and neuromuscular blockers;

c) Patient vigil and without agitation;

d) Absence of fever or new infection;

e) Hemodynamically stable;

f) Absence of metabolic and/or electrolytic disorders;

g) Effective cough;

h) Patient with an inspired oxygen fraction less than or equal to $40 \%\left(\mathrm{FiO}_{2} \leq 40 \%\right)$ and positive endexpiratory pressure less than or equal to $5 \mathrm{~cm} \mathrm{H}_{2} \mathrm{O}$ (PEEP $\leq 5 \mathrm{~cm} \mathrm{H}_{2} \mathrm{O}$ ) with $\mathrm{SaO}_{2}>90 \%$ and ratio of arterial oxygen pressure by the fraction of inspired oxygen greater than $200\left(\mathrm{PaO}_{2} / \mathrm{FiO}_{2}>200\right)$;

i) Tidal volume greater than $5 \mathrm{~mL} . \mathrm{kg}^{-1}\left(\mathrm{~V}_{\mathrm{T}}>5 \mathrm{~mL} . \mathrm{kg}^{-1}\right)$; j) Maximum inspiratory pressure less than $20 \mathrm{~cm} \mathrm{H}_{2} \mathrm{O}$ $\left(\mathrm{MIP}<20 \mathrm{~cm} \mathrm{H}_{2} \mathrm{O}\right)$;

l) $\mathrm{RR} / \mathrm{V}_{\mathrm{T}}<105$ breaths. $\mathrm{min}^{-1} \cdot \mathrm{L}^{-1}$;

m) $R R \leq 35$ breaths per minute (rpm).

We excluded patients accidentally extubated $(n=4)$, tracheostomized $(n=24)$, and those who did not meet the essential criteria for weaning $(n=6)$.

Clinical and demographic data (Table 1) were collected from medical records and, in dubious cases, from doctors and physiotherapists.

Patients who presented with improvement of the condition that lead to VM, hemodynamic stability, oxygenation parameters mentioned above and absence of fever were subjected to the following screening measures, using the ventilator Vela (Viasys, USA) for monitoring:

1) Static compliance (Cst), with sedated patient, in volume control mode, and performing an inspiratory pause;

2) Minute volume (VE) and RR, with unsedated patient, awake and on PSV mode of $7 \mathrm{~cm} \mathrm{H}_{2} \mathrm{O}, \mathrm{FiO}_{2} \leq 40 \%$ and PEEP = $5 \mathrm{~cm} \mathrm{H}_{2} \mathrm{O}$ for one minute;

3) $V_{T}$ : resulted from the division of VE by RR;

Table 1 Clinical Characteristics of 166 Patients on Mechanical Ventilation.

\begin{tabular}{|c|c|}
\hline \multicolumn{2}{|l|}{ Clinical Characteristics } \\
\hline Age (years $\pm \mathrm{DP})$ & $53 \pm 22$ \\
\hline Female, $\mathrm{n}$ & 72 \\
\hline Male, $\mathrm{n}$ & 94 \\
\hline Death, n (\%) & $29(17.5)$ \\
\hline Discharge, n (\%) & $137(82.5)$ \\
\hline $\begin{array}{l}\text { Duration of } M V \text { before weaning (days } \pm \\
\text { DP) }\end{array}$ & $4 \pm 3.6$ \\
\hline Weaning success, n (\%) & $127(76.5)$ \\
\hline Weaning failure (SBT failure), n (\%) & $29(17.5)$ \\
\hline Extubation failure, n (\%) & $10(6)$ \\
\hline \multicolumn{2}{|l|}{ MV cause, $\mathrm{n}(\%)$} \\
\hline Pneumonia & $23(13.8)$ \\
\hline Nonrespiratory sepsis & $13(7.8)$ \\
\hline Coma & $17(10.2)$ \\
\hline Chronic obstructive pulmonary disease & $4(2.4)$ \\
\hline Asthma & $3(1.8)$ \\
\hline Postoperative & $43(25.9)$ \\
\hline Acute Pulmonary Edema & $16(9.6)$ \\
\hline Shock & $5(3.0)$ \\
\hline Bronchoaspiration & $8(4.8)$ \\
\hline Convulsion & $7(4.2)$ \\
\hline Exogenous intoxication & $12(7.2)$ \\
\hline Drowning & $3(1.8)$ \\
\hline Metabolic acidosis & $4(2.4)$ \\
\hline Arrhythmias & $3(1.8)$ \\
\hline Stridor & $1(0.6)$ \\
\hline Traumatic brain injury & $1(0.6)$ \\
\hline Miscellany & $3(1.8)$ \\
\hline
\end{tabular}

SD: standard deviation; $\mathrm{n}$ : number of occurrences; SBT: spontaneous breathing trial. 
4) $R R / V_{T}$ : resulted from the division of $R R$ by $V_{T}$ in liters;

5) MIP was measured from the inspiratory occlusion valve.

During screening measurements, patients who had Cst > $25 \mathrm{~mL} . \mathrm{cm} \mathrm{H}_{2} \mathrm{O}^{-1} ; \mathrm{RR} \leq 35 \mathrm{bpm} ; \mathrm{V}_{\mathrm{T}}>5 \mathrm{~mL} . \mathrm{kg}^{-1}$, $\mathrm{f} / \mathrm{V}_{\mathrm{T}}<105$ breaths. $\mathrm{min}^{-1}$. $\mathrm{L}^{-1} ;$ MIP $<-20 \mathrm{~cm} \mathrm{H}_{2} \mathrm{O}$ underwent SBT for 30 minutes on PSV mode of $7 \mathrm{~cm} \mathrm{H}_{2} \mathrm{O}, \mathrm{FiO}_{2} \leq 40 \%$ and $P E E P=5 \mathrm{~cm} \mathrm{H}_{2} \mathrm{O}$. RR, VE, and $\mathrm{V}_{\mathrm{T}}$ were recorded during SBT, minute by minute, using the respirator monitor. Additionally, vital signs data and pulse oximetry were recorded continuously on a multiparameter monitor. Throughout the test, the physiotherapist and/or doctor on duty constantly monitored the patient looking for signs of SBT failure ${ }^{1}$, namely:
a) $\mathrm{RR}>35 \mathrm{bpm}$;
b) $\mathrm{RR} / \mathrm{V}_{\mathrm{T}}>105$ breaths. $\mathrm{min}^{-1} \cdot \mathrm{L}^{-1}$;
c) $\mathrm{SaO}_{2}<90 \%$;
d) Tachycardia $>140 \mathrm{bpm}$ or $\geq 20 \%$ increase;
e) Systolic blood pressure $<90 \mathrm{~mm} \mathrm{Hg}$ or $>180 \mathrm{~mm} \mathrm{Hg}$ or $\geq 20 \%$ increase;
f) Arrhythmias;
g) Psychomotor agitation and/or reduced level of consciousness;
h) Dyspnea.

In the presence of any signs described, SBT was interrupted and the patient placed in a ventilation mode that would provide comfort. Data collection was performed by the investigators or by a previously trained physiotherapy team.

\section{Outcomes}

a) Weaning success: the patient underwent SBT, was extubated, and without mechanical ventilation for more than 48 hours;

b) Weaning failure: the patient had signs of SBT failure;

c) Extubation failure: the patient underwent SBT and was extubated, but returned to $\mathrm{MV}$ within 48 hours after extubation.

All patients were followed-up until discharge or death in the ICU.

\section{Statistical Analysis}

Continuous variables were expressed as mean and standard deviation and categorical variables as frequency and percentage. Mann-Whitney test and Fisher's exact test were used to compare nonparametric variables and Student's t-test to compare parametric variables. The following parameters were used to assess the predictive power of RR: sensitivity (SE), specificity (SP), positive predictive value (PPV), negative predictive value (NPV), likelihood ratio for a positive test $(\mathrm{LR}+)$, likelihood ratio for a negative test (LR-), accuracy, and area under the ROC curve. The statistical programs used were MedCalc version 11.5.1.0 and BioEstat version 5.0 10,11. A p-value $<0.05$ was considered significant.

\section{Results}

In total, 166 patients were evaluated during weaning from MV from March 2009 to August 2011. The mean age of the study population was $53 \pm 22$ years, with 94 males and 72 females, and mean duration of MV before weaning was $4 \pm 3.6$ days. Postoperative period was the most common cause of MV $(25.9 \%)$, followed by pneumonia $(13.8 \%)$, coma $(10.2 \%)$, acute pulmonary edema $(9.6 \%)$, sepsis $(7.8 \%)$, exogenous intoxication $(7.2 \%)$, aspiration $(4.8 \%)$, and seizures $(4.2 \%)$ (Table 1).

At the end of the study, 137 (82.5\%) patients were discharged from the ICU and 29 (17.5\%) died in that unit. Weaning success occurred in 127 (76.5\%); weaning failure in 29 patients (17.5\%), and extubation failure in 10 patients $(6 \%)$.

Of the patients with weaning failure, $100 \%$ presented with RR > 24 bpm during screening measurement and SBT (Graphic 1 and Table 2). This pattern of tachypnea remained throughout SBT up to suspension, with the onset of signs of SBT failure. The major cause of extubation failure was acute pulmonary edema (APE), present in five out of 10 patients (50\%), followed by bronchospasm in three patients $(30 \%)$. The two remaining cases of failure were laryngeal edema and respiratory infection (Table 3 ).

There was a lower mortality rate $(12.6 \%)$ among patients with weaning success $(16 / 127)$, followed by the rate $(20.7 \%)$ among patients with weaning failure $(6 / 29)$. Patients with extubation failure had the highest mortality rate $(70 \%)$, and compared with that observed among the successes, the difference was statistically significant ( $p=0.0001)$.

Considering the best cut-off point as RR > $24.19 \mathrm{bpm}$, the RR generated by the ROC curve presented the following predictive power for weaning failure: SE $100 \%$, SP $85 \%$, NPV 100\%, PPV 60\%; LR+ 6.68; LR- 0.00, and accuracy $88 \%$ $(p<0.0001$; Table 2 and Graphic 1). During screening and SBT stages, RR behavior was characterized by increased weaning failure $(R R=31 \pm 6 \mathrm{bpm})$ and normal among successes $(R R=19 \pm 5 \mathrm{bpm})(p<0.0001)$. There was no difference in RR behavior among patients with extubation failure (RR $=18 \pm 6 \mathrm{bpm})$ compared to the success cases $(R R=19 \pm 5 \mathrm{bpm}) ; \mathrm{p}=0.7313$.

\section{Discussion}

On average, $46 \%$ of the patients admitted to the ICU require $\mathrm{MV}$ as fundamental life support, but this procedure is associated with significant rates of morbidity and mortality, which are directly proportional to the duration of $M V$ and weaning failure 5,6,12-16. The need to develop new strategies to remove the patient from $M V$ as early as possible is evident. According to Coplin et al. ${ }^{7}$, delayed extubation was associated with a statistically significant increase in mortality (RR for death 2.2, 95\% Cl: 1.0-4.7). Boles et al. ${ }^{1}$ have proposed the early investigation of weaning capacity to avoid its delay.

A systematic daily evaluation of the possibility of weaning is an independent predictor of successful extubation and survival ${ }^{12}$. In this context, the investigation of predictors that, combined with clinical experience, improve the success rates of weaning is essential and justified our study.

The rates of weaning success $(76.5 \%)$ and failure $(23.5 \%)$ in the present study are close to those reported in the literature $\left(70 \%\right.$ and $30 \%$, respectively $\left.{ }^{1}\right)$. The causes of $\mathrm{MV}$ were similar to those found in the literature: postoperative (25.9\%), pneumonia (13.8\%), coma (10.2\%), APE (9.6\%), and sepsis $(7.8 \%)^{17,18}$. 
Table 2 Predictive Power of Respiratory Rate for Different Cut-off Points in 156 Patients during Weaning (127 weaning successes and 29 failures).

\begin{tabular}{|c|c|c|c|c|c|c|}
\hline Criteria & Sensitivity & $95 \% \mathrm{Cl}$ & Specificity & $\mathrm{Cl} 95 \%$ & LR+ & LR- \\
\hline$\geq 6.6022$ & 100.00 & $88.1-100.0$ & 0.00 & $0.0-2.9$ & 1.00 & \\
\hline$>24.1935^{*}$ & 100.00 & $88.1-100.0$ & 85.04 & $77.6-90.7$ & 6.68 & 0.00 \\
\hline > 24.7857 & 96.55 & $82.2-99.9$ & 85.04 & $77.6-90.7$ & 6.45 & 0.041 \\
\hline > 24.9806 & 96.55 & $82.2-99.9$ & 86.61 & $79.4-92.0$ & 7.21 & 0.040 \\
\hline$>25$ & 93.10 & $77.2-99.2$ & 86.61 & $79.4-92.0$ & 6.96 & 0.080 \\
\hline$>25.4984$ & 93.10 & $77.2-99.2$ & 89.76 & $83.1-94.4$ & 9.10 & 0.077 \\
\hline$>25.7016$ & 89.66 & $72.6-97.8$ & 89.76 & $83.1-94.4$ & 8.76 & 0.12 \\
\hline$>25.8146$ & 89.66 & $72.6-97.8$ & 90.55 & $84.1-95.0$ & 9.49 & 0.11 \\
\hline$>25.871$ & 86.21 & $68.3-96.1$ & 90.55 & $84.1-95.0$ & 9.12 & 0.15 \\
\hline$>26.2581$ & 86.21 & $68.3-96.1$ & 92.91 & $87.0-96.7$ & 12.16 & 0.15 \\
\hline$>26.4929$ & 79.31 & $60.3-92.0$ & 92.91 & $87.0-96.7$ & 11.19 & 0.22 \\
\hline$>26.5565$ & 79.31 & $60.3-92.0$ & 94.49 & $89.0-97.8$ & 14.39 & 0.22 \\
\hline$>26.6452$ & 75.86 & $56.5-89.7$ & 94.49 & $89.0-97.8$ & 13.76 & 0.26 \\
\hline$>26.7271$ & 75.86 & $56.5-89.7$ & 95.28 & $90.0-98.2$ & 16.06 & 0.25 \\
\hline > 27.2257 & 68.97 & $49.2-84.7$ & 95.28 & $90.0-98.2$ & 14.60 & 0.33 \\
\hline > 27.9091 & 68.97 & $49.2-84.7$ & 96.06 & $91.1-98.7$ & 17.52 & 0.32 \\
\hline$>28.6478$ & 62.07 & $42.3-79.3$ & 96.06 & $91.1-98.7$ & 15.77 & 0.39 \\
\hline > 29.0862 & 62.07 & $42.3-79.3$ & 96.85 & $92.1-99.1$ & 19.71 & 0.39 \\
\hline$>29.7419$ & 48.28 & $29.4-67.5$ & 96.85 & $92.1-99.1$ & 15.33 & 0.53 \\
\hline$>30.1121$ & 48.28 & $29.4-67.5$ & 98.43 & $94.4-99.8$ & 30.66 & 0.53 \\
\hline$>32.9173$ & 20.69 & $8.0-39.7$ & 98.43 & $94.4-99.8$ & 13.14 & 0.81 \\
\hline$>33.0968$ & 20.69 & $8.0-39.7$ & 99.21 & $95.7-100.0$ & 26.28 & 0.80 \\
\hline$>33.1108$ & 17.24 & $5.8-35.8$ & 99.21 & $95.7-100.0$ & 21.90 & 0.83 \\
\hline$>33.2673$ & 17.24 & $5.8-35.8$ & 100.00 & $97.1-100.0$ & & 0.83 \\
\hline$>48.8333$ & 0.00 & $0.0-11.9$ & 100.00 & $97.1-100.0$ & & 1.00 \\
\hline
\end{tabular}

$\mathrm{Cl}$ : confidence interval; LR+: likelihood ratio for a positive test; LR-: likelihood ratio for a negative test; *: best cut-off point.

Table 3 Clinical Characteristics of 10 Reintubated Patients.

\begin{tabular}{|c|c|c|c|c|c|c|}
\hline Sex & Age (years) & Intubation cause & $\begin{array}{l}\text { Reintubation } \\
\text { cause }\end{array}$ & $\begin{array}{l}\text { Time interval } \\
\text { for reintubation } \\
\text { (hours) }\end{array}$ & Outcome & Observation \\
\hline Male & 72 & $\mathrm{AMI} / \mathrm{APE}$ & APE & 12 & Death & \\
\hline Female & 54 & Sepsis/UTR & APE & 6 & Death & WBC 17200 \\
\hline Female & 62 & APE/SAH & APE & 6 & Death & WBC 31900 \\
\hline Male & 65 & Uremia & APE & 24 & Death & WBC 20300 \\
\hline Female & 68 & $\mathrm{CHF}$ & APE & 4 & Death & \\
\hline Male & 79 & Sepsis & BESP & 12 & ICU discharge & \\
\hline Male & 75 & Seizures & BESP & 4 & ICU discharge & \\
\hline Female & 64 & PO & BESP & & Death & WBC 15400 \\
\hline Female & 29 & Pneumonia & Stridor & 6 & ICU discharge & 1 previous FE \\
\hline Male & 77 & Aspiration & Pneumonia & 24 & Death & \\
\hline
\end{tabular}

AMI: acute myocardial infarction; APE: acute pulmonary edema, UTR: pneumonia; WBC: white blood cell count; SAH: systemic arterial hypertension, CHF: congestive heart failure; BESP: bronchospasm; EF: extubation failure.

Extubation failure (EF) was associated with higher mortality rate $(70 \%)$. Several studies show that EF is associated with increased mortality ${ }^{2,3,6,18-20}$. According to Epstein et al. ${ }^{6}$, the mortality rate in patients with EF was $43 \%$ compared to $12 \%$ among those with weaning success $(p<0.0001)$.
We found that the 10 patients with EF showed behavior patterns similar to those of successful patients during both screening and SBT stages. RR remained normal in both groups; therefore, it had no predictive power. 


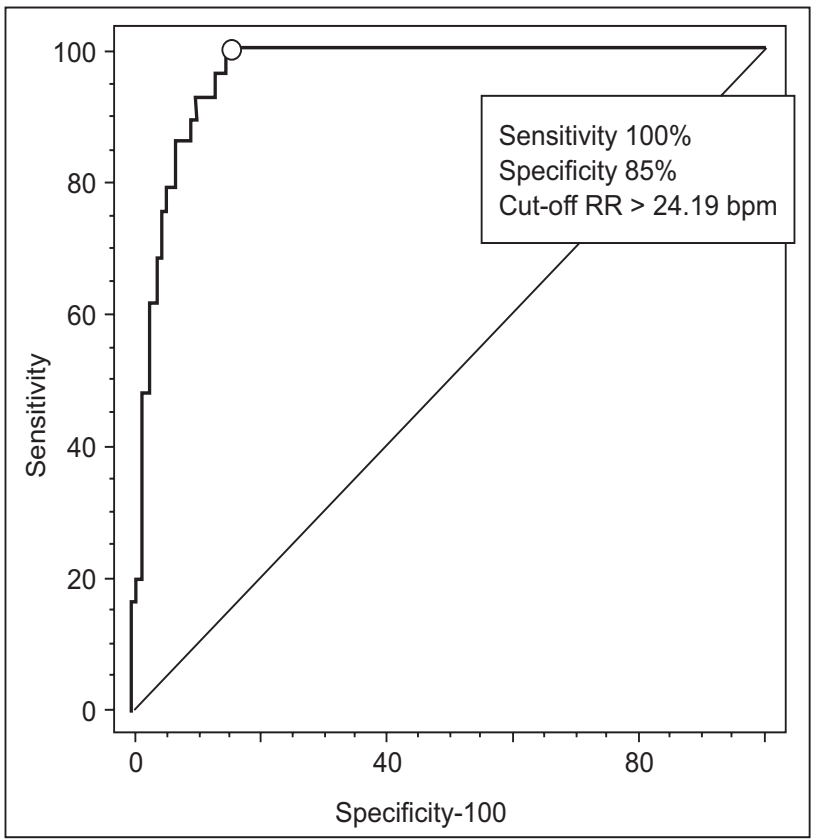

Graphic 1 ROC Curve of Respiratory Rate and Best Cut-off Point in 156 patients (127 weaning successes and 29 failures). $\mathrm{RR}$ : respiratory rate; bpm: breaths per minute.

Identifying patients with the possibility of extubation failure remains a major challenge for all who study weaning. The current predictive indices do not distinguish patients who, after a satisfactory SBT, will be reintubated from those who will be successfully extubated ${ }^{3,19}$.
In our series, the group of patients who were reintubated was characterized by elderly individuals (mean age $64 \pm 15$ years); 40\% had severe comorbidities (AMI Killip class III, CHF, SAH, renal failure), and $40 \%$ had significant leukocytosis (over 15,000), which could indicate an underlying inflammatory process, a new or persistent infection. One patient had laryngeal edema after two tracheal intubations and another had pneumonia 24 hours after extubation (Table 3). According to Esteban et al. ${ }^{3}$, respiratory failure leading to reintubation is due to conditions arising after extubation, such as bronchospasm, laryngeal edema, and pneumonia. In our patients, cardiovascular comorbidities (CHF, SAH, AMI) predispose the occurrence of APE, the most frequent cause of reintubation (50\%). Study of conditions leading to reintubation should create strategies to reduce EF rates ${ }^{3}$. It is noteworthy that the rate of reintubation of $6 \%$ was lower than that reported in the literature (13\%) ${ }^{1}$, which may be due to the rigor of including only patients who met all essential criteria for weaning.

During analysis, RR proved to be a practical and efficient predictive index (SE 100\%, SP $85 \%$, and accuracy $88 \%$ for a cutoff point of RR > $24 \mathrm{bpm}$ ), able to identify $100 \%$ of patients with weaning failure during screening and SBT stages on PSV mode. In other words, all patients with weaning failure had a RR > 24 bpm during the screening stage and maintained it during SBT.

There were $15 \%$ of false positive cases of weaning success with RR > 24 rpm; in these patients, the response to mental suffering or adaptation to pathological conditions was identified (Table 4), with increased RR during screening and SBT stages, without cardiorespiratory involvement. In this context, the continuous monitoring of patients by the team that identified the conditions responsible for isolated tachypnea

Table 4 Conditions Related to Respiratory Rate (RR) > 24.19 bpm and Weaning Success (false positive) in 19 Patients.

\begin{tabular}{lll}
\hline RR $(\mathrm{bpm})$ & Condition & Management during SBT \\
\hline 25 & Attempted suicide/odynophagia & Analgesia and anxiolytic \\
26 & ICH sequel/paresis & Observation \\
33 & Pulmonary fibrosis & Observation \\
27 & Pneumonia treatment & Observation \\
29 & IS/CRF/AF sequel & Observation \\
25 & Congestion & Diuretics and fluid restriction \\
26 & Anxiety and agitation & Anxiolytic \\
25 & Abdominal pain & Analgesia \\
25 & IS sequel/coma vigil & Observation \\
26 & CHF/EF = 34\% & Observation \\
26 & Anxiety and agitation & Anxiolytic \\
25 & Pneumonia treatment & Observation \\
25 & Congestion & Diuretics and fluid restriction \\
26 & Anxiety and agitation & Anxiolytic \\
33 & Anxiety and agitation & Anxiolytic \\
28 & Chronic asthma/dehydration & Rehydration \\
30 & Compensated metabolic acidosis & Observation \\
26 & Anxiety and agitation & Observation \\
30 & Attempted suicide & Anxiolytic \\
\hline
\end{tabular}

$\mathrm{ICH}$ : intracerebral hemorrhage; SBT: spontaneous breathing trial; IS: ischemic stroke; CRF: chronic renal failure, AF: atrial fibrillation, CHF: congestive heart failure, EF: ejection fraction. 
and correctly chose weaning was important. Patients with psychiatric disorders characterized by psychomotor agitation were treated with doses of sedative for anxiety, which enabled the weaning process.

\section{Conclusion}

In this study population, RR was an efficient predictor of weaning failure easy to be recorded from the respirator, exempting calculations by the assistants. In the initial screening phase, RR > $24 \mathrm{bpm}$ was present in $100 \%$ of patients who would have a weaning failure during SBT (sensitivity $100 \%$ ). RR $\leq 24 \mathrm{bpm}$ was found in the initial stage of screening in $85 \%$ of patients who would have a weaning success (specificity $85 \%$ ). The $15 \%$ of false positive cases (successful weaning with RR > $24 \mathrm{bpm}$ ) are acceptable and were identified by clinical evaluation. A predictor of weaning failure has to have a sensitivity of $100 \%$, even if it involves some loss of specificity, because it decreases the chance of early MV discontinuation and associated cardiorespiratory risks. In this study, the best cut-off point of 24 bpm generated by the ROC curve suggests that the cut-off points of 35 and 38 , mentioned in the literature, are too high for our reality ${ }^{1,8}$.

\section{References}

1. Boles JM, Bion J, Connors A et al. - Weaning from mechanical ventilation. Eur Respir J, 2007; 29(5):1033-1056.

2. Esteban A, Alía I, Tobin MJ et al. - Effect of spontaneous breathing trial duration on outcome of attempts to discontinue mechanical ventilation. Spanish Lung Failure Collaborative Group. Am J Respir Crit Care Med, 1999;159(2):512-518.

3. Esteban A, Alía I, Gordo F et al. - Extubation outcome after spontaneous breathing trials with T-tube or pressure support ventilation. The Spanish Lung Failure Collaborative Group. Am J Respir Crit Care Med, 1997;156(2 Pt 1):459-465.

4. Esteban A, Alía I - Weaning from mechanical ventilation. Crit Care, 2000;4(2):72-80.

5. Torres A, Gatell JM, Aznar M et al. - Reintubation increases the risk of nosocomial pneumonia in patients needing mechanical ventilation. Am J Respir Crit Care Med, 1995;152(1):137141.

6. Epstein SK, Ciubotaru RL, Wong JB - Effect of failed extubation on the outcome of mechanical ventilation. Chest, 1997;112(1):186192.
7. Coplin WM, Pierson DJ, Cooley KD et al. - Implications of extubation delay in brain-injured patients meeting standard weaning criteria. Am J Respir Crit Care Med, 2000;161(5):15301536.

8. Meade M, Guyatt G, Cook D et al. - Predicting success in weaning from mechanical ventilation. Chest, 2001; 120(Suppl 6):400S4245.

9. Nemer SN, Barbas CS, Caldeira JB et al. - A new integrative weaning index of discontinuation from mechanical ventilation. Crit Care, 2009;13(5):R152.

10. MedCalc 11.5.1.0. Disponível em: http://www.medcalc.org/ download.php. Acessado em: 11/9/2011.

11. BioEstat 5. Disponível em: http://www.mamiraua.org.br/ download/. Acessado em: 11/9/2011.

12. Ely EW, Baker AM, Evans GW et al. - The prognostic significance of passing a daily screen of weaning parameters. Intensive Care Med, 1999;25(6):581-587.

13. De Lassence A, Alberti C, Azoulay E et al. - Impact of unplanned extubation and reintubation after weaning on nosocomial pneumonia risk in the intensive care unit. A prospective multicenter study. Anesthesiology, 2002;97(1):148-156.

14. American Thoracic Society - Guidelines for the management of adults with hospital-acquired, ventilator-associated, and healthcare-associated pneumonia. Am J Respir Crit Care Med, 2005;171(4):388-416.

15. Esteban A, Alía I, Ibañez J et al. - Spanish lung collaborative group. Modes of mechanical ventilation and weaning. A national survey of Spanish hospitals. Chest, 1994;106(4):11881193.

16. Yamauchi LY - Falência do desmame: risco, fatores associados e prognóstico de pacientes sob ventilação mecânica prolongada [Tese]. São Paulo, Faculdade de Medicina, Universidade de São Paulo, 2004, p. 87.

17. Esteban A, Anzueto A, Frutos F et al. - Characteristics and outcomes in adult patients receiving mechanical ventilation. A 28-day international study. JAMA, 2002;287(3):345-355.

18. Seymour CW, Martinez A, Christie JD et al. - The outcome of extubation failure in a community hospital intensive care unit: a cohort study. Crit Care, 2004;8(5):R322-R327.

19. Vallverdú I, Calaf N, Subirana M et al. - Clinical characteristics, respiratory functional parameters, and outcome of a two-hour T-piece trial in patients weaning from mechanical ventilation. Am J Respir Crit Care Med, 1998;158(6):1855-1862.

20. Perren A, Domenighetti G, Mauri S et al. - Protocol-directed weaning from mechanical ventilation: clinical outcome in patients randomized for a $30-\mathrm{min}$ or 120 -min trial with pressure support ventilation. Intensive Care Med, 2002;28(8):10581063. 